\title{
Assessment and Treatment of Anxiety in Children with Autism Spectrum Disorder in School Settings: A Systematic Review and Meta-Analysis
}

\author{
Celal Perihan' ${ }^{1} \cdot$ Ali Bicer $^{2} \cdot$ Joel Bocanegra ${ }^{3}$ \\ Accepted: 8 June 2021 / Published online: 18 June 2021 \\ (c) The Author(s), under exclusive licence to Springer Science+Business Media, LLC, part of Springer Nature 2021
}

\begin{abstract}
Anxiety is the most common mental health problem that occurs with Autism Spectrum Disorder (ASD), and due to creating a more inclusive learning environment, children with ASD are placed in general education classrooms. Thus, addressing anxiety problems for children with ASD in school settings become critically important. This systematic review and meta-analysis investigated the current qualities of studies and the effects of school-based interventions for reducing anxiety in children with ASD. The study included six studies with a total of 165 participants. A random-effect meta-analysis yielded a moderate overall effect $(g=-0.58,95 \% \mathrm{CI}[-0.96,-0.20], z=-3.01, p<.05)$ with no significant heterogeneity, $Q(5)=7.31, p=0.20$. Findings of the systematic review indicated that school-based interventions for anxiety problems are still in the early stages, and studies showed significant issues with adaptations of current clinical-based interventions and anxiety measurements to use in school settings for children with ASD. Interpretation of these findings and implications are discussed.
\end{abstract}

Keywords Anxiety $\cdot$ Autism $\cdot$ ASD $\cdot$ School-based intervention

\section{Introduction}

Autism spectrum disorder (ASD) is a lifelong neurodevelopmental disability that causes severe impairments in individuals' social and communication skills with repetitive behaviors and interests (APA, 2013). Prevalence estimates of ASD have increased dramatically over the past decades, and ASD has become one of the most common disability categories in the USA. Currently, 1 in every 59 children has been

Celal Perihan

pericela@isu.edu

Ali Bicer

abicer@uwyo.edu

Joel Bocanegra

bocajoel@isu.edu

1 Department of Teaching and Education Studies, Idaho State University, 62 E Terry St, Room 108C, Pocatello, USA

2 School of Teacher Education, University of Wyoming, Wyoming Hall, Room 451, Laramie, WY 82071, USA

3 Department of School Psychology and Educational Leadership, Idaho State University, 62 E Terry St, Room 108A, Pocatello, USA diagnosed with ASD (Maenner et al., 2020). Unsurprisingly, because of the high prevalence estimates of ASD, treating and educating children with ASD have been focused on by researchers, and schools have offered a range of supports to children with ASD at different levels to meet their educational and behavioral needs (Ferraioli \& Harris, 2011). More specifically, researchers have focused on interventions with a structured applied behavior analysis (ABA) approach to minimize inappropriate behaviors of children with ASD, and as of today, various evidence-based practices (EBP) have been developed, including social skills interventions, to help children with ASD in externalizing problems (Reichow \& Volkmar, 2010). In contrast to this, related literature showed that many of these studies have overlooked internalizing behaviors while focusing on externalizing problems. For instance, although many evidence-based programs, including social stories, targeted visual supports, the Program for the Education and Enrichment of Relational Skills (PEERS), and the Social Communication, Emotional Regulation, and Transactional Support (SCERTS) model have demonstrated improvement in targeted skills, such as emotional regulation and communication skills, that can be evidence of effectiveness in treatments of internalizing problems in children with ASD (Rutherford et al., 2019). These programs have 
not targeted or have not reported improvement of anxiety or depression symptoms in children with ASD, which makes the effects of these interventions in internalizing problems uncertain. Indeed, a relevant literature review noticed that children with ASD are more likely to exhibit one or more mental health difficulties (Vasa \& Mazurek, 2015). Recent limited studies also support that internalizing problems may predict externalizing problems in children with ASD. For instance, recently, Bos and colleagues (2018) examined a correlation between internalizing and externalizing problems in children with and without ASD, and they noted some internalizing problems, including levels of worry/ rumination, were significant predictors in externalizing problems for boys with ASD. Furthermore, recent studies have also identified internalizing problems as a predictor of being a victim of bullying (Cappadocia et al, 2012). Cappadocia and colleagues showed that children with autism and internalizing problems are 11 times more likely to be victimized in bullying compared to students who have ASD without internalizing problems. Therefore, the identification and treatment of internalizing problems in children with ASD should be prioritized to minimize behavioral and social failures.

Anxiety is an excessive feeling of worry about a variety of events and activities over a long period (DSM-IV, 2013). Compared to typically developing children, anxiety is the most common mental health problem that children with ASD experience in their school and social life (Vasa \& Mazurek, 2015). Several studies have shown evidence that the prevalence of anxiety disorders in children with ASD differs significantly, ranging from 42 to $84 \%$, with nearly $40 \%$ meeting a diagnostic criterion for anxiety disorders (Van Steensel et al., 2011; Simonoff et al., 2008). The prevalence of anxiety symptoms in ASD is also much higher than the prevalence of anxiety (7.1\%) in typically developing children aged 2-17 years (Ghandour et al., 2018) and in other specific disability categories (Gillott et al., 2001). The high rates of anxiety symptoms, along with the significant variations in prevalence that are estimated in the literature, support the idea that anxiety symptoms may cause a broad range of challenges in children with ASD (Luxford et al., 2016). Unfortunately, anxiety symptoms are usually inner-directed, and most of these symptoms are invisible and not easily detectable by other individuals (Ginsburg et al., 2008). In addition to the complexity of diagnoses in anxiety, due to unique factors related to children with ASD characteristics, including the overlap of symptoms in anxiety with ASD and the unique anxiety symptoms of children with ASD, the identification of anxiety symptoms in children with ASD needs further investigations (Wood \& Gasow, 2010). Relevant literature using multiple assessments across the different informants is assessing anxiety symptoms of children with ASD to minimize inaccurate conclusions (Vasa et al., 2015). In addition, both diagnoses and treatments of anxiety in children with ASD have been conducted and completed in clinical settings by clinicians who have more knowledge related to unique anxiety symptoms in typically developing children (Perihan et al., 2020a, 2020b). Despite that, the significant variations of the prevalence estimate in the literature show the inconsistency in the identification of anxiety symptoms in children with ASD (Van Steensel et al., 2011; Simonoff et al., 2008). One of the most common reasons for the variations in the prevalence estimates might be the use of measurements, with some changes or modifications, that were designed to measure anxiety in typically developing children (Perihan et al., 2020a, 2020b). Although measurements such as Spence children's anxiety scale-parent and children versions (SCAS; Spence, 1997); the Screen for Child Related Anxiety Disorders-child and parent versions (SCARED; Birmaher et al., 1999) have excellent psychometric properties in typically developing children, it is still unclear how these measurements address unique anxiety symptoms of children with ASD. For instance, Kerns and colleagues (2014) investigated the common and unique anxiety symptoms of 59 children with ASD, and the adequacy of the DSM definition of anxiety. The finding of the study noted that $15 \%$ of youth presented unique anxiety symptoms while $31 \%$ of them showed both traditional and unique anxiety symptoms. Further, evaluating these unique anxiety symptoms with the DSM-IV criteria demonstrated that DSM-IV failures to identify these symptoms in children with ASD might cause to conclude inaccurate and significant variant results related to anxiety disorders in children with ASD with existed measurements. Similarly, a recent metaanalysis (Perihan et al., 2020a, 2020b) showed that children with ASD receive existing treatments, such as Facing Your Fears (Reaven et al., 2011) or variations of CBT programs with or without adaptations. Although these clinical-based treatments are found effective to reduce anxiety symptoms in children with ASD, it is still unclear how these interventions meet the unique needs of children with ASD. For example, existing clinical anxiety programs for typically developing children are based on communication and relationship between clients and therapists. Since students with ASD have both social and communication difficulties, they may struggle to interact with therapists and understand both social and emotional contexts that are essential to success within these treatments (Safronoff et al., 2005). In contrast, relevant literature demonstrated that visualization is one of the most effective strategies in promoting effective social interaction and communication with ASD. A few studies showed that with current communication methods in anxiety treatments without adaptations, children with ASD are less likely to benefit from the treatments and similarly, some studies showed that making necessary changes in current programs, such as using visualized language show significant improvements in the success of anxiety treatments in 
children with ASD (Ekman \& Hiltunen, 2015). In addition to these challenges in clinical treatments, children with ASD have less access to community health services (Montes et al., 2009). Due to a lack of access to mental health services, the rate of children with ASD that receive appropriate mental health treatment is even less than typically developing children, and literature showed that only $20 \%$ of children with ASD can receive mental health services (Bromley at el., 2004). As of today, with the coronavirus restrictions, such as the closure of schools, the limited opportunities for students with ASD to access mental health services have become even less (Kalvin et al., 2021). Despite that, these children spend most of their time in school settings without a diagnosis, and most of the children are placed in regular classroom settings due to full inclusion requirements. These barriers to accessing adequate mental health treatments make schools and teachers even more important in the treatment of anxiety problems in children with ASD.

Despite the important role that schools play in the treatment of these children, there is a lack of research and knowledge related to general and special education teachers' responses and understanding of anxiety-related behaviors in children with ASD. Trudgen and Lawn's study (2011) showed that only $20 \%$ of teachers received training in anxiety for typically developing children, and the prevalence of teachers trained for anxiety in children with ASD is estimated to be even lower. Due to core ASD symptoms (Clarke et al., 2016) and lack of teacher's knowledge about anxiety in ASD, children with ASD might face more serious misunderstandings in the diagnosis of anxiety problems than typically developing children. For example, Rodgers (2016) noted that although school refusal is considered as a core feature of separation anxiety in typically developing children, it cannot be accurate for children with ASD because they are likely to avoid going to a school due to other factors, including sensory overload or disruption of daily routines. In addition to that, The COVID-19 pandemic has caused significant changes in the daily routines of children with ASD, these children have faced significant unique mental health distress and challenges (SPARK, 2020). Because of the lack of knowledge and training, it is common for anxiety in children with ASD to go unnoticed by teachers until their symptoms become more harmful and visible. Inadequate and reduced mental health services increase the risk of children with ASD placed in school environments without diagnosis and treatment of anxiety. That may cause further impacts on their ability to interact with others and may increase the risk of educational failures, isolation from society, substance use, or other long-term psychological problems (van Steensel et al., 2011). Currently, few studies have addressed the impacts of anxiety on children's academic achievements (Bellini et al., 2007). Thus, awareness of anxiety in children with ASD in a school environment is particularly critical to make accurate diagnoses related to anxiety symptoms in children with ASD and to provide appropriate treatment options or referrals to health or other professionals to meet the individual needs of students with ASD. Therefore, researchers need to develop and identify types of interventions that are appropriate and effective for implementing within schools for children with ASD.

\section{Purpose and Research Questions}

As of today, most children with ASD have limited access to community health services. Therefore, schools are a unique environment where both general and special education teachers are the first responders to support anxiety issues in children with ASD. Although research in ASD has provided a few treatment options for anxiety symptoms in clinical settings, there is still a gap between research and practices in school settings. Most children with ASD are placed and spend their time in general or special education classroom settings with necessary modifications and supports in several areas, but treatment options for anxiety symptoms in children with ASD are still limited. These limited investigations of treatment options that have been conducted in school settings for treating anxiety in children cause significant delays in making correct referrals (Baker et al., 2008). Until recently, few studies have focused on testing the identification and treatment of anxiety in children with ASD, and no studies have existed examining the overall effects of current school-based or home-schooled collaborated interventions for anxiety problems of children with ASD. Meta-analytic studies of the literature also support this conclusion. For instance, a recent meta-analytic study (Perihan et al., 2020a, 2020b) has not examined the studies from school perspectives, and the findings did not include any information related to strengths, weaknesses, or needs of school-based anxiety treatments for children with ASD. Thus, it is critically important to provide and improve treatment options for anxiety in children in school settings to decrease the risk factors for children with ASD. In this study, specific research questions were,

1. What are the characteristics of current school-based anxiety treatments in ASD?

2. What is the overall efficacy of school-based treatments to reduce anxiety symptoms in children with ASD?

3. What are the important needs of today's literature to improve the treatment of anxiety in school settings?

\section{Method}

\section{Search Procedures}

The current study followed The Preferred Reporting Items for Systematic Reviews and Meta-analyses (PRISMA; 
Moher et al., 2009) protocol for the searching process. The electronic databases of PsycINFO, Eric, ProQuest, and RefWorks were searched to identify potential studies. Google Scholar was also searched to help identify as many relevant studies as possible. The literature search included studies containing one of the following keywords: "anxiety," "autism," "ASD," "mental health," "social-emotional development," and "school-based intervention." The keywords were used alone or in combination to identify potential studies for inclusion. Due to the limited number of publications, the initial search included all published studies up to 2020 .

Following the first search, studies were evaluated and included in this review if they; (1) included participants with a primary diagnosis of ASD, (2) indicated participants had anxiety disorders or exhibited high levels of anxiety, (3) implemented school-based intervention or a home-school collaboration model that focused on decreasing anxiety symptoms, and/or (4) reported at least one standardized measure of anxiety. Studies were excluded if they were not published in peer-reviewed journals in English. Descriptive studies were excluded from the current study. The literature search returned with 6 studies (see Fig. 1).

\section{Coding of Study Coding Reliability}

Two Ph.D. level researchers coded the studies independently for the following information; study name, sample size, age (mean; SD), gender, treatment, control group, treatment modality, study design, anxiety measures, and effect size (Hedges' g; see Table 1 for characteristics of the included studies). Researchers coded the studies independently. The percentage of agreement was used to calculate the InterCoder Reliability (IRA). The formula for the IRA was the ratio of agreements multiplied by the total number of agreements plus disagreements divided by 100 (House et al., 1981). The IRA for the study was $95 \%$.

\section{Calculation of Effect Size and Meta-Analytic Procedures}

Since each study had different variables, the study used a random-effects meta-analysis method to examine the overall effect of the included studies. To express efficacies of treatments that used different psychometric scales, Standardized Mean Difference, also known as Cohen's $d$, was used (Borenstein et al., 2021). Cohen's $d$ was calculated as effect size (ES) with the mean difference scores of control and experimental groups at the post-treatment scores then dividing the result by the pooled standard deviation $(n=5)$. For one study (Drmic et al., 2017), Cohen's $d$ was calculated given $r$ as an effects size that has been calculated with corresponding Chi-square. The majority of studies $(n=5)$ used more than one type of outcome measurement, thus, the effect sizes were combined and averaged for each study (as suggested in Lipsey \& Wilson, 2001). Extended literature showed that Cohen's $d$ is biased in small sample size studies which cause slight changes in calculating the overall effect in a meta-analysis (Hedges, 1981). Therefore, all the effect sizes were converted from Cohen's $d$ to Hedge's $g$ with 95\% confidence intervals (CI) for minimizing the biases due to small sample sizes and the possibility of the standard error of effect sizes (Lipsey \& Wilson, 2001). The Hedge's $g$ formula is similar to Cohen's $d$ and uses mean difference scores of control and experimental groups at the post-treatment then dividing the result by the pooled standard deviation while Cohen's $d$ uses the pooled standard deviation. Negative effect sizes for both Cohen's $d$ and Hedge's $g$ indicate the effect of interventions on decreasing the mean of anxiety symptoms. The weighted mean estimate of the effect sizes was then calculated with Hedges' $g$ to demonstrate the overall effectiveness. Cochran's $Q$-statistic (Cochran, 1954) was used to test heterogeneity within the studies to detect the moderators of treatment response. The study also included forest and funnel plots for illustrating the relative strength of treatment effects and possible publication biases (Sterne \& Egger, 2001).

\section{Results}

Initially, 552 citations were identified through initial search after removing duplicates, but most of these citations were related to ASD, not anxiety $(n=497)$ or they were not experimental studies $(n=18) .55$ citations were screened for full text, and 26 of the studies were excluded because either they were not school-based $(n=15)$, including children with only ASD $(n=5)$, follow-up studies $(n=2)$, or adult population $(n=2)$. Two studies only could not be included in the final review because the effect sizes could not be calculated based on given information. As a result, six studies were found to have met the initial inclusion criteria.

The total of six ES estimates across the included studies was between $(g)-2.06$ to -0.12 . The weighted overall effect size of school-based interventions for anxiety in children with ASD was found effective, $g=-0.58$, 95\% CI $[-0.96,-0.20], z=-3.01, p<0.05$ (see Fig. 2 for effects sizes and confidence intervals across all of the studies at $95 \% \mathrm{CI}$ ) with no significant heterogeneity (see Fig. 3), $Q(5)=7.31, p=0.20$. The funnel plot has identified Fujii et al. (2013) as an outlier but removing Fujii et al. (2013) did not cause significant changes in the 


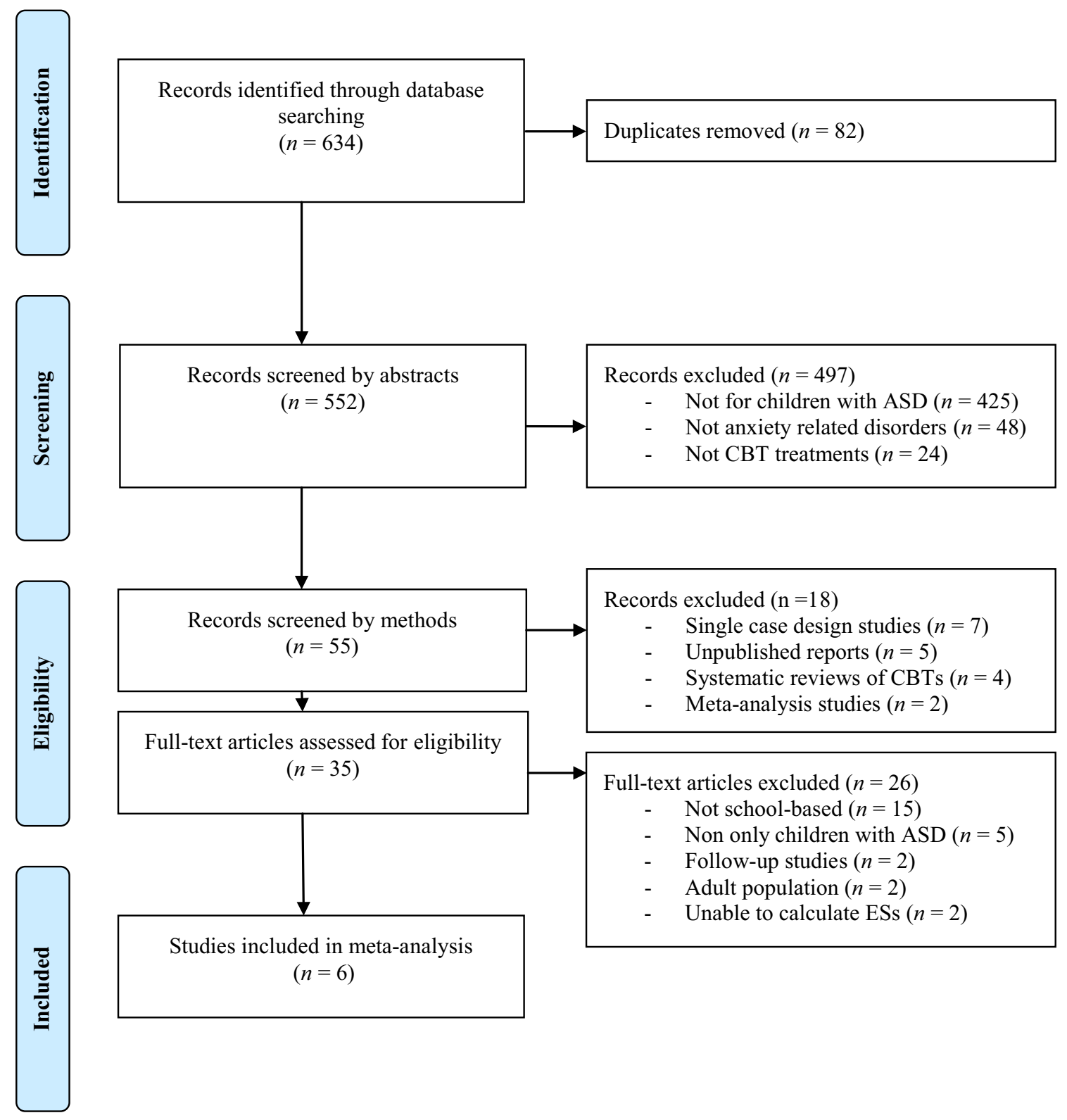

Fig. 1 Flow diagram of the study selection for meta-analysis

findings $(g=-0.47,95 \%$ CI $[-0.86,-0.07], z=-2.32$, $p<0.05)$.

\section{Study and Intervention Characteristics}

Six studies were included in the final review with 165 participants (109 participants were located in experimental groups while 56 of the participants were in the control groups). Of the five studies that included gender, 95 participants were male (58\%), and 70 were female (42\%). The ages of participants were between 5 and 21 years. All studies included participants from special education settings. Only two of the included studies (Fujii et al.,
2013; Clarke et al., 2016) reported participants' racial or ethnic backgrounds (see Table 2 for characteristics of the participants).

Five following interventions were implemented in six studies; the Exploring Feelings (Attwood, 2004; $n=2$ ), Adapted Facing Your Fears (Reaven et al., 2011;n=1) and Adapted CBT programs $(n=2)$, and MASSI (White et al., 2010; $n=1)$. Two studies used only the Exploring Feelings intervention (Clarke et al., 2017; Luxford et al., 2016). Three studies used adapted versions of clinical interventions while three studies implemented interventions that were designed specifically for children with ASD (Exploring Feelings; $M A S S I)$. Treatment length varied from 6 to 32 weeks with 
Table 1 Characteristics of the included studies

\begin{tabular}{|c|c|c|c|c|c|c|c|c|c|}
\hline $\begin{array}{l}\text { Author } \\
\text { (year) }\end{array}$ & Sample size & Age (M; SD) & Gender & Treatment & $\begin{array}{l}\text { Control } \\
\text { group }\end{array}$ & $\begin{array}{l}\text { Treatment } \\
\text { modality }\end{array}$ & $\begin{array}{l}\text { Study } \\
\text { design }\end{array}$ & $\begin{array}{l}\text { Outcome } \\
\text { measures }\end{array}$ & $\begin{array}{l}\text { Effect Size } \\
(g)\end{array}$ \\
\hline $\begin{array}{l}\text { Clarke et al. } \\
\text { (2017) }\end{array}$ & 28 & $\begin{array}{l}(12.64 ; .85) \\
(12.86 \\
0.7)\end{array}$ & 28 (female) & $\begin{array}{c}\text { Exploring } \\
\text { feelings }\end{array}$ & $\begin{array}{c}\text { Treatment- } \\
\text { as-usual }\end{array}$ & $\begin{array}{l}6 \text { weekly }-1 \mathrm{~h} \\
\text { sessions }\end{array}$ & $\begin{array}{l}\text { A quasi- } \\
\text { experi- } \\
\text { mental } \\
\text { design }\end{array}$ & $\begin{array}{l}\text { SCAS (P) } \\
\text { SCAS (C) }\end{array}$ & $\begin{array}{l}-0.66 \\
-0.62\end{array}$ \\
\hline $\begin{array}{l}\text { Drmic et al. } \\
\text { (2017) }\end{array}$ & 44 & $\begin{array}{l}\text { 13-15 } \\
\text { (NR;NR) }\end{array}$ & $\begin{array}{l}6 \text { (female) } \\
38 \text { (male) }\end{array}$ & $\begin{array}{l}\text { Adapted } \\
\text { Facing } \\
\text { Your Fears } \\
\text { (FYF) }\end{array}$ & $\begin{array}{l}\text { No control } \\
\text { group }\end{array}$ & $\begin{array}{l}10 \text { weekly } \\
60-90 \text { min. } \\
\text { sessions }\end{array}$ & $\begin{array}{l}\text { A mix- } \\
\text { method } \\
\text { design }\end{array}$ & $\begin{array}{l}\text { SCARED } \\
(\mathrm{P}) \\
\text { SCARED } \\
(\mathrm{C}) \\
\text { DBC (T) }\end{array}$ & $\begin{array}{l}-0.31 \\
-1.01 \\
-0.01\end{array}$ \\
\hline $\begin{array}{l}\text { Fujii et al. } \\
\text { (2012) }\end{array}$ & 12 & $\begin{array}{l}7-11(8.8 ; \\
1.6)\end{array}$ & $\begin{array}{l}3 \text { (female) } \\
9 \text { (male) }\end{array}$ & $\begin{array}{l}\text { Adapted } \\
\text { Building } \\
\text { Confidence } \\
\text { CBT pro- } \\
\text { gram }\end{array}$ & $\begin{array}{l}\text { Treatment- } \\
\text { as-usual }\end{array}$ & $\begin{array}{l}32 \text { weekly } \\
90 \text { min. ses- } \\
\text { sions }\end{array}$ & $\begin{array}{l}\text { A hybrid } \\
\text { study } \\
\text { design }\end{array}$ & $(\mathrm{C} / \mathrm{P})-\mathrm{ADIS}$ & -2.06 \\
\hline $\begin{array}{l}\text { Ireri et al. } \\
\text { (2019) }\end{array}$ & 40 & $\begin{array}{l}\text { 5-21 (NR: } \\
\text { NR) }\end{array}$ & $\begin{array}{l}13 \text { (female) } \\
17 \text { (male) }\end{array}$ & MASSI & $\begin{array}{l}\text { Treatment- } \\
\text { as-usual }\end{array}$ & $\begin{array}{l}13 \text { weekly } \\
\text { individual } \\
60 \text { min. ses- } \\
\text { sions }\end{array}$ & $\begin{array}{l}\text { An experi- } \\
\text { mental } \\
\text { design }\end{array}$ & $\begin{array}{l}\text { CASI-Anx } \\
\text { (P) }\end{array}$ & -0.39 \\
\hline $\begin{array}{l}\text { Luxford } \\
\text { et al. } \\
\text { (2016) }\end{array}$ & 35 & $\begin{array}{l}11-14(13.2 ; \\
1.1)\end{array}$ & $\begin{array}{l}4 \text { (female) } \\
31 \text { (male) }\end{array}$ & $\begin{array}{r}\text { Exploring } \\
\text { Feelings }\end{array}$ & A waitlist & $\begin{array}{l}6 \text { weekly }-1 \mathrm{~h} \\
\text { sessions }\end{array}$ & $\begin{array}{l}\text { An experi- } \\
\text { mental } \\
\text { design }\end{array}$ & $\begin{array}{l}\text { School } \\
\text { Anxiety } \\
\text { Scale (P) } \\
\text { SCAS-(C) } \\
\text { SCAS-(P) }\end{array}$ & $\begin{array}{l}-0.20 \\
-0.42 \\
-0.57\end{array}$ \\
\hline $\begin{array}{c}\text { Ooi et al. } \\
\text { (2008) }\end{array}$ & 6 & $\begin{array}{c}9-13 \text { (11.50: } \\
0.84)\end{array}$ & NR & $\begin{array}{l}\text { Adapted } \\
\text { CBT pro- } \\
\text { gramme }\end{array}$ & $\begin{array}{l}\text { No control } \\
\text { group }\end{array}$ & $\begin{array}{l}16 \text { 90-min } \\
\text { weekly ses- } \\
\text { sions }\end{array}$ & $\begin{array}{l}\text { Pre- experi- } \\
\text { mental } \\
\text { design }\end{array}$ & $\begin{array}{l}\text { Asian } \\
\text { children } \\
\text { anxiety } \\
\text { scale (T) } \\
\text { SCAS-(C) } \\
\text { SCAS-(P) }\end{array}$ & $\begin{array}{l}-0.28 \\
-0.33 \\
0.23\end{array}$ \\
\hline
\end{tabular}

$A D I S$ Anxiety disorders Interview schedule, CASI-Anx Child and adolescent symptom inventory-4-ASD anxiety scale, DBC Developmental behavioral checklist, $(C)$ child version, MASSI The multimodal anxiety and social skills intervention, $(P)$ parent version, SCARED The Screen for Child Related Anxiety Disorders, $(T)$ Teacher version, SCAS Spence children's anxiety scale, $(T)$ Teacher version

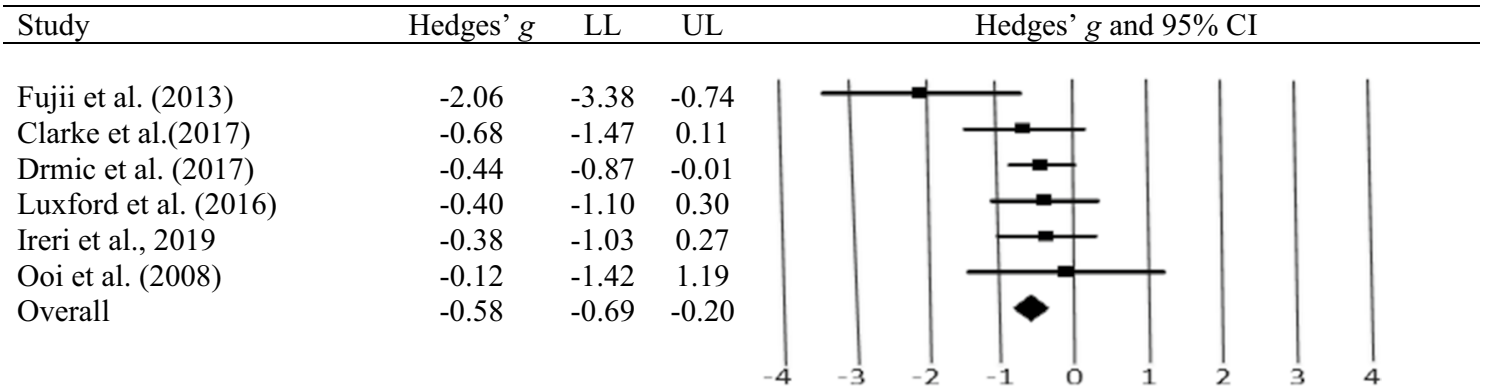

\footnotetext{
Note. A horizontal line represents the $95 \%$ confidence intervals of each study. The black box represents the effect size of the study. The diamond represents the overall effects across studies. Negative effect sizes indicate improvement in treatment groups. $\mathrm{LL}=$ lower limit; $\mathrm{UL}=$ upper limit.
}

Fig. 2 Forest plot of studies included in the meta-analysis

60 to 90 min. sessions. Only one study (Fujii et al., 2013) used longer than 16 weeks of treatment protocol (32 weeks). All six programs have been designed based on CBT principles. Overall, all programs included three distinct parts.
The first part included psychoeducation to teach students how to understand feelings and emotions. The second part aimed to teach anxiety management techniques to cope with anxiety symptoms, including deep breathing, and relaxation, 


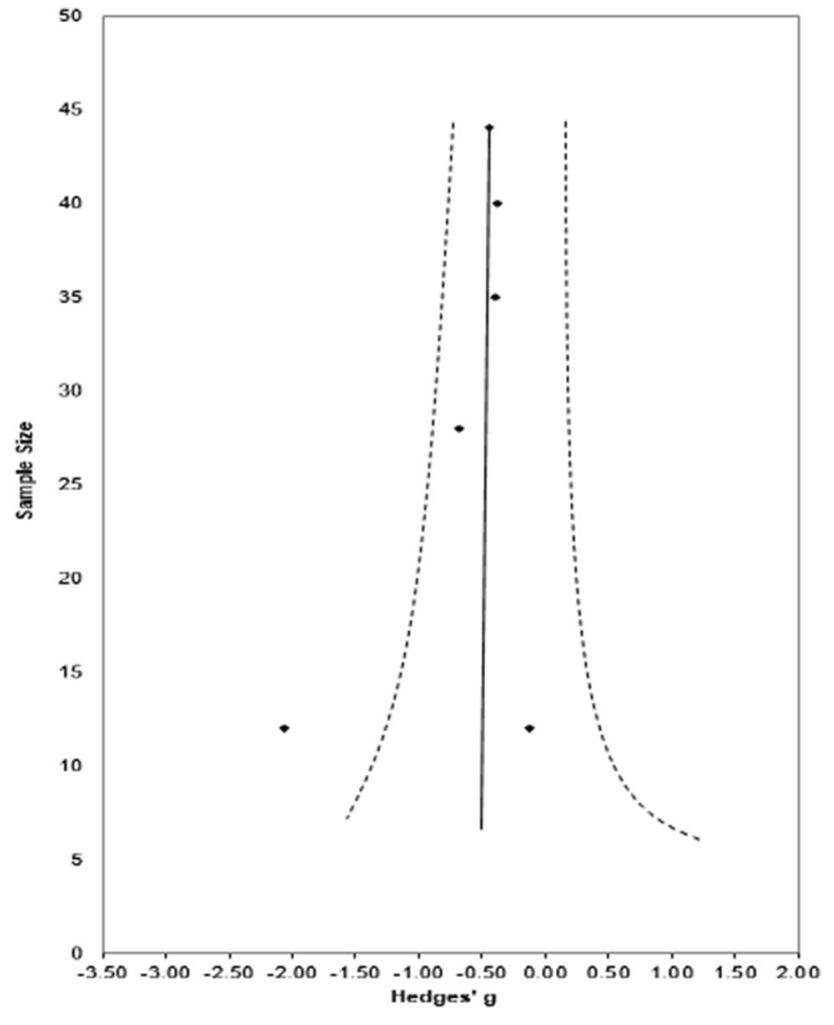

Fig. 3 Funnel plot of sample size by Hedges' $g$ for the included studies

problem-solving, and cognitive self-control strategies. The third part included graded exposure strategies. Both Exploring Feelings and MASSI programs included some specific strategies that promote the generalization of skills for children with ASD to school and community settings. Most of the studies used visual cues and social stories for children with ASD. Ooi et al., (2008) used a specific problem-solving strategy (STAR procedure). Fujii et al. (2013) delivered the programs as a home-school collaboration model and used in vivo parent training. The length of this program also was extended to 32 weeks. Two other programs ( FYF and $M A S S I)$ made similar changes to their length to adapt to the school calendar. All programs delivered in small group contexts, and each group consisted of three (Ooi et al., 2008) to six participants (Luxford et al., 2016). Both Clarke et al. (2016) and Ireri et al. (2019) offered one-to-one support to participants. Only Fujii et al. (2013) and Drmic et al. (2017) involved parents in their study while other studies included only students as participants.

\section{Dependent Variables}

Only anxiety measurements were reported in this study. The following nine different types of measurements were
Table 2 Characteristics of the participants

\begin{tabular}{lll}
\hline Variable & $n$ & $\%$ \\
\hline $\begin{array}{l}\text { Number of participants } \\
\text { Experimental group }\end{array}$ & 109 & 66.1 \\
Control group & 56 & 33.9 \\
Gender & & 57.6 \\
Male & 95 & 42.4 \\
Female & 70 & $\%$ \\
Variable & $\mathrm{N}(\mathrm{n})$ & \\
Level of education & & 50 \\
Elementary education & $3(18)$ & 33 \\
Secondary education & $2(107)$ & 17 \\
Kindergarten to secondary education & $1(40)$ & 68 \\
Racelethnicity & & 32 \\
White British & $2(26)$ & \\
Caucasian & $2(9)$ & \\
Variable & Range \\
Age (years) & $5-21$ & \\
IQ Scores & $76-157$ & \\
\hline
\end{tabular}

$I Q$ Intelligence quotient, $N$ Number of studies, $n=$ number of participants

used; Spence Children's Anxiety Scale-Parent and Child Versions (SCAS; Spence, 1997; $n=6$ ); the Screen for Child Related Anxiety Disorders-Child and Parent versions (SCARED; Birmaher et al., 1999; $n=2$ ), the Anxiety Disorders Interview Schedule: Child and Parent versions (ADIS-C/P; Silverman \& Albano, 1996; $n=2$ ), Developmental-Behavioral Checklist-Teacher (DBC-T; Einfeld \& Tonge, 2002; $n=1$ ), the Child and Adolescent Symptom Inventory-4 ASD Anxiety Scale (CASI-Anx; Sukhodolsky et al., 2008; $n=1$ ), School Anxiety Scale (Lyneham et al., 2008; $n=1$ ), and the Asian Children Anxiety ScaleCaretaker Version (ACAS; Koh et al., 2002; $n=1$ ). All studies included at least one report from parents while five of the six studies reported child reports. Two of the studies (Drmic et al., 2017; Ooi et al., 2008) performed teacher reports. Most of the outcome measurements were designed to assess anxiety in typically developing children. Only the Child and Adolescent Symptom Inventory-4 ASD Anxiety Scale (CASI-ASD-Anxiety; Sukhodolsky et al., 2008) was designed for measuring anxiety in children with ASD. Two studies reported (Drmic et al., 2017; Ooi et al., 2008) subdomain scores of measurements with total scores while other included studies $(n=4)$ reported only total anxiety scores. Drmic et al., (2017) provided subdomain scores for SCARED-P/C (Panic/somatic; Generalized anxiety; Separation anxiety; Social anxiety; School avoidance) and for $D B C$ - $T$ (Disruptive/antisocial; Self-absorbed; Communication disturbance; Anxiety; Social relating). Ooi et al. 
(2008) also provided subdomains for $S C A S-P$ (Social anxiety; Obsessive-compulsive behavior).

\section{Discussion}

The present study is the first study that aims to explain the characteristics of current school-based anxiety treatments and demonstrate the overall efficacy of school-based anxiety interventions for children with ASD. Although there are limited studies in the relative literature, the findings of this meta-analytic study showed that school-based interventions are effective $(g=-0.58)$ for decreasing anxiety symptoms in children with ASD. Although, the current finding was slightly $(g=0.66)$ lower than the recent metaanalytic study that evidenced the efficacy of clinic-based interventions for anxiety symptoms in children with ASD across different settings (Perihan et al., 2020a, 2020b). The results of this study supported the use of school-based interventions to treat anxiety symptoms in children with ASD. The current results can help educators and practitioners close the gap between research and practice in schools since initial results support the beneficial effects of anxiety treatments in school settings. The transferring of anxiety treatments for ASD from research to practice in school settings is in the early phase, and results of the systematic review noted two considerable issues with schoolbased intervention for children with ASD; adaptations of both the anxiety measurements and current clinical-based interventions for use in schools to identify and treat anxiety in children with ASD.

The findings of this study showed a need for specific anxiety measurements for children with ASD. A variety of instruments that were developed for assessing clinical anxiety symptoms in typically developing children have been used for children with ASD. Although most of these measurements, including RCMAS (Reynolds \& Richmond, 1985), MASC (March et al., 1999), and SCAS (Spence, 1998) have excellent psychometric properties in typically developing children, both validities and reliabilities of these measurements in ASD are still being investigated and need more clarifications. For example, recently, Carruthers and colleagues (2020) have tested the psychometric properties of the SCAS and SCARED in ASD. The finding showed that although both measurements had appropriate internal consistency, a parent-child agreement was still fair to good. The broader reason for potential differences in psychometric properties of these measurements between typically developing children and ASD would be the unusual anxiety symptoms and core features of children with ASD. As Kerns and colleagues (2014) demonstrated, youth with ASD presents unique anxiety symptoms, which might not be identified by current DSM-IV criteria. These measurements should able to identify these unique anxiety symptoms and lead to more accurate conclusions. For example, gaze avoidance and the lack of social skills, which are the most known characteristics of autism, could be linked to social anxiety disorders (Kleberg et al., 2016). Also, most of the children with ASD meet the criteria of social anxiety disorders if they are measured with current measurements that are designed for typically developing children (White et al. 2009). Outcome measurements without appropriate adaptations may fail to explain whether the symptoms stem from anxiety disorders or core features of ASD. Relevant literature showed that there are limited numbers of available measures that have been developed for individuals with ASD to detect these unique symptoms of anxiety in children with ASD (White et al., 2012). Due to the lack of available instruments, most of the studies have used existing anxiety measurements whether without or limited modifications for assessing anxiety levels in children with ASD. The modifications usually were completed by adding screening questions related to anxiety in children with ASD without considering both emotional and cognitive developments of children with ASD. The findings of previous research also support this conclusion. For example, Grondhuis and Aman (2012) identified 36 different measurements that have been used to measure anxiety symptoms, and most of them have not been validated in children with ASD. Parallel to this finding, only one assessment (CASI-Anx) was designed specifically for children with ASD has been used in the six included studies. The finding of this study showed that school-based programs have a similar issue related to assessing anxiety in children with ASD. Only two studies (Drmic et al., 2017; Ooi et al., 2008) used teacher reports (DBC-T; Einfeld \& Tonge, 2002 and ACAS; Koh et al., 2002). More interestingly, the psychometric properties of these school measurements were advocated based on the findings of only one study, thus the validity and reliability of these teacher reports need further investigation. The significant overlap between ASD and anxiety symptoms with a lack of appropriate teacher measurements may also cause dilemmas in diagnoses of anxiety disorders in children with ASD in schools. For example, as Rodgers (2016) noted a variety of anxiety symptoms in children with ASD can be present because of core features of autism and environmental factors, such as sensory overload, fear of separation from their parents, and disruption of daily routines (e.g., Drmic et al., 2017; Ireri et al., 2019). Similarly, children with ASD might have more specific fears in school settings such as fear of using a school bus, staying in a small room, and social phobia. Typically developing children might have different fears, such as fear of making mistakes by answering questions, a bad grade, taking a test, and be more fearful of animals than children with ASD (Evans et al., 2005). Therefore developing reliable and valid anxiety measurements for children with ASD, especially in 
school settings, may be particularly important for adapting or improving best practices in this population to meet their unique needs.

Another important finding of this study was the number of issues related to transferring current clinic-based interventions into school settings. In school settings, it is important to consider a variety of unique environmental factors that may impact the efficacy of interventions (Owens et al., 2014), including time and resource limitations (i.e., mental health professionals, school psychologists). Thus, clinical-based interventions should make necessary changes or modifications according to the unique features of school environments. For instance, since social interactions are likely to exist more in school environments, school-based interventions need to address students' social problems in school settings to minimize the existence of anxiety problems and increase the efficacy of the treatment programs in children with ASD. Similarly, the implementation of the clinical programs during the year (32 weeks with $90 \mathrm{~min}$ sessions) may not be an option for most schools, as well as families, because of a lack of resources. Unfortunately, most of the included studies used interventions without adaptations to specific circumstances that may be faced in school settings or failed to mention or explain how social problems might influence the efficacy of these interventions in children with ASD. Further, studies have not yet explained which specific strategies can help students to engage in social interaction with their peers in school environments. The systematic review showed that most studies used current CBT-based treatments in school settings with or without modifications and the qualities of these modifications remain unclear and limited. The most common modifications were adjustments of visual cues and social stories (Clarke et al., 2016; Ooi et al., 2008). In addition to these adjustments, Drmic et al. (2017) included more strategies for children with ASD including the incorporation of special interests, use of video self-modeling without explanations based on research. Only Fujii et al. (2013) used specific strategies to minimize the social isolation of children with ASD, which included teaching friendship skills to make the treatment more ASD-specific. Despite this, many studies identified specific practices, including targeted visual supports, social communication groups, or social thinking for improvements in emotional regulation and communication skills in school settings to help children with ASD. Future studies also need to consider adding these strategies to CBT-based programs or using these strategies as alternatives to CBT-based interventions. Using these alternative strategies will also help teachers lead the anxiety intervention in school settings without extra support from clinical professionals. Although the initial feasibilities and acceptabilities of CBT programs are strong (Drmic et al., 2016), included studies showed that teachers' roles in CBT-based interventions are still unclear.
For instance, Drmic et al. (2017) and Luxford et al. (2016) used educators, including special educators, to implement programs with coaching and noted significant reeducation in both children and parent reports. In contrast, Fujii et al. (2013) and Ireri et al. (2019) included teachers in programs to help the students with transferring and practicing the skills they learned during treatments over to the school environments, rather than leading the programs. Unlike all of these roles, some studies (Clarke et al., 2016; Ooi et al., 2008) included only doctorate students and researchers from educational psychology, psychology, and psychiatry, not teachers. Although the findings of the two studies (Drmic et al., 2017; Luxford et al., 2016) showed the interventions that were lead by teachers may be comparably effective for decreasing anxiety symptoms to the intervention led by clinical professionals, the different roles of educators across different studies cause uncertainties in the impacts of teachers in the efficacy of these interventions. Due to limited clinical professionals in both school and community settings, teachers should able to intervene in anxiety issues of children with ASD without needing clinical professionals. The finding of this study also showed that identifying and providing training programs for teachers to implement clinical-based practices is also another weakness and needs to be studied in detail by future studies. Most of the studies have not provided sufficient information related to the training teachers participating in the treatment programs received for anxiety in children with ASD (Clarke et al., 2016; Ireri et al., 2019). Yet, the literature still needs to develop evidence-based practices for teachers to lead interventions with limited consultations or appropriate training programs.

The current study also highlighted some differences in characteristics of participants from the literature, which is important to conclude whether anxiety treatment might be effective in a school setting and to generalize the findings of this study. The first interesting finding was that $42 \%$ of the total participants were female. This rate is higher than the reported 4:1 male/female ratio typically reported in studies with gender differences in the diagnosis of ASD (Maenner et al., 2020). To date, there are limited studies examining gender differences in anxiety problems among children with ASD. Recently, Sedgewick and colleagues (2020) indicated that girls in ASD are more likely to experience internalizing problems than boys. The finding of this study supports this conclusion, as the rate of females included in the study is disproportionate to the rate of females diagnosed with ASD. Similarly, studies included participants with IQ scores of at least 70 or above. The first and most important potential reason for selecting high-functioning participants could be types of treatments. All studies used CBT-based treatments which require a variety of prerequisite cognitive skills such as emotional recognition and metacognition skills to cope with internalizing problems (Lickel et al., 2012). Thus, it 
was assumed that children would need high cognitive functioning to benefit from these treatments. The findings of Lickel and colleagues (2012) also noted a significant positive correlation between the effectiveness of CBT treatments and the IQs of participants. Against this prediction, literature demonstrated that at least $30 \%$ of the individuals with ASD have an intellectual disability (IQ $<70$; Christensen et al., 2019). Moreover, studies showed that children with lower IQ are more likely to exist higher anxiety issues in children with ASD (Edirisooriya et al., 2020; Rosa et al., 2016). Although existing studies have demonstrated the effects of both clinical and school-based treatments in anxiety among children with high functioning autism, more research in the diagnosis and treatment of anxiety disorder in children with ASD and intellectual disability is needed. Therefore, future studies need to test the effectiveness of both new and existing treatments in children with ASD and lower IQs.

\section{Limitations}

Although the findings of the current study prove that school-based interventions may be beneficial in the anxiety treatment of children with ASD, the study should be interpreted in the context of limitations. One major limitation of this study was the limited number of included studies. The related literature has limited studies, and anxiety treatment of children with ASD is a recently focused area in the relative literature. Thus, the current study includes only six studies. Due to the limited number of included studies, the current study could not complete moderator analyses. Future meta-analytic studies need to include more studies to confirm the efficacy of school-based interventions and examine possible moderators. One of the possible moderators could be types of settings. Findings from this study demonstrated that all studies selected their participants from special education schools and settings, and no one implemented the treatments in general education settings. It was assumed that each country has different approaches to teach students with ASD, and three of the included studies' countries had separate special education schools. In the USA, due to law and inclusive education, children with ASD are placed in a regular classroom with typically developing peers. Therefore, these findings should be interpreted with caution due to the lack of implementation in general education classrooms. To generalize these findings to other settings, future studies should implement anxiety treatments in this population in general education settings.

Funding The authors received no financial support for the research and publication of this article.

\section{Declarations}

Conflict of interest The authors have no conflicts of interest to disclose.

\section{References}

American Psychiatric Association. (2013). Diagnostic and statistical manual of mental disorders (DSM-5®). American Psychiatric Pub.

Attwood, T. (2004). Exploring feelings: Cognitive behaviour therapy to manage anxiety. Future Horizons.

Baker, J. A., Grant, S., \& Morlock, L. (2008). The teacher-student relationship as a developmental context for children with internalizing or externalizing behavior problems. School Psychology Quarterly, 23(1), 3.

Bellini, S., Peters, J. K., Benner, L., \& Hopf, A. (2007). A meta-analysis of school-based social skills interventions for children with autism spectrum disorders. Remedial and Special Education, 28(3), 153-162.

Borenstein, M., Hedges, L. V., Higgins, J. P., \& Rothstein, H. R. (2021). Introduction to meta-analysis. John Wiley and Sons.

Bos, M. G., Diamantopoulou, S., Stockmann, L., Begeer, S., \& Rieffe, C. (2018). Emotion control predicts internalizing and externalizing behavior problems in boys with and without an autism spectrum disorder. Journal of Autism and Developmental Disorders, 48(8), 2727-2739.

Bromley, J., Hare, D. J., Davison, K., \& Emerson, E. (2004). Mothers supporting children with autistic spectrum disorders: Social support, mental health status and satisfaction with services. Autism, 8, 409-423.

Birmaher, B., Brent, D. A., Chiappetta, L., Bridge, J., Monga, S., \& Baugher, M. (1999). Psychometric properties of the screen for child anxiety related emotional disorders (SCARED): A replication study. Journal of the American Academy of Child and Adolescent Psychiatry, 38(10), 1230-1236. https://doi.org/10.1097/ 00004583-199910000-00011

Carruthers, S., Kent, R., Hollocks, M. J., \& Simonoff, E. (2020). Brief report: Testing the psychometric properties of the spence children's anxiety scale (scas) and the screen for child anxiety related emotional disorders (scared) in autism spectrum disorder. Journal of Autism and Developmental Disorders, 50(7), 2625-2632.

Cappadocia, M. C., Weiss, J. A., \& Pepler, D. (2012). Bullying experiences among children and youth with autism spectrum disorders. Journal of Autism and Developmental Disorders, 42(2), 266-277.

Christensen, D. L., Maenner, M. J., Bilder, D., Constantino, J. N., Daniels, J., Durkin, M. S., \& Dietz, P. (2019). Prevalence and characteristics of autism spectrum disorder among children aged 4 years-early autism and developmental disabilities monitoring network, seven sites, United States, 2010, 2012, and 2014. MMWR Surveillance Summaries, 68(2), 1.

Clarke, C., Hill, V., \& Charman, T. (2017). School based cognitive behavioural therapy targeting anxiety in children with autistic spectrum disorder: A quasi-experimental randomised controlled trail incorporating a mixed methods approach. Journal of Autism and Developmental Disorders, 47(12), 3883-3895.

Cochran, W. G. (1954). The combination of estimates from different experiments. Biometrics, 10, 101-129.

Cohen, J. (1992). Statistical power analysis. Current Directions in Psychological Science, 1(3), 98-101. Buna bak sildin burden.

Drmic, I. E., Aljunied, M., \& Reaven, J. (2017). Feasibility, acceptability and preliminary treatment outcomes in a school-based CBT intervention program for adolescents with ASD and anxiety 
in Singapore. Journal of Autism and Developmental Disorders, 47(12), 3909-3929.

Edirisooriya, M., Dykiert, D., \& Auyeung, B. (2020). IQ and Internalising Symptoms in Adolescents with ASD. Journal of Autism and Developmental Disorders, pp. 1-21.

Einfeld, S. L., \& Tonge, B. J. (2002). Manual for the developmental behaviour checklist: Primary carer version $(D B C-P)$ and teacher version $(D B C-T)$ (2nd ed.). Monash University Centre for Developmental Psychiatry and Psychology.

Ekman, E., \& Hiltunen, A. J. (2015). Modified CBT using visualization for autism spectrum disorder (ASD), anxiety and avoidance behavior-a quasi-experimental open pilot study. Scandinavian Journal of Psychology, 56(6), 641-648.

Evans, D. W., Canavera, K., Kleinpeter, F. L., Maccubbin, E., \& Taga, K. (2005). The fears, phobias and anxieties of children with autism spectrum disorders and down syndrome: Comparisons with developmentally and chronologically age matched children. Child Psychiatry and Human Development, 36(1), 3-26.

Ferraioli, S. J., \& Harris, S. L. (2011). Effective educational inclusion of students on the autism spectrum. Journal of Contemporary Psychotherapy, 41(1), 19-28.

Fujii, C., Renno, P., McLeod, B. D., Lin, C. E., Decker, K., Zielinski, K., \& Wood, J. J. (2013). Intensive cognitive behavioral therapy for anxiety disorders in school-aged children with autism: A preliminary comparison with treatment-as-usual. School Mental Health, 5(1), 25-37.

Ghandour, R. M., Sherman, L. J., Vladutiu, C. J., Ali, M. M., Lynch, S. E., Bitsko, R. H., \& Blumberg, S. J. (2019). Prevalence and treatment of depression, anxiety, and conduct problems in US children. The Journal of Pediatrics, 206, 256-267.

Grondhuis, S. N., \& Aman, M. G. (2012). Assessment of anxiety in children and adolescents with autism spectrum disorders. Research in Autism Spectrum Disorders, 6(4), 1345-1365.

Gillott, A., Furniss, F., \& Walter, A. (2001). Anxiety in high-functioning children with autism. Autism, 5(3), 277-286.

Ginsburg, G. S., Becker, K. D., Kingery, J. N., \& Nichols, T. (2008). Transporting CBT for childhood anxiety disorders into inner-city school-based mental health clinics. Cognitive and Behavioral Practice, 15, 148-158.

Hedges, L. V. (1981). Distribution theory for glass's estimator of effect size and related estimators. Journal of Educational Statistics 6 (2), 107-28 Sage Publications Sage, Thousand Oaks

House, A. E., House, B. J., \& Campbell, M. B. (1981). Measures of interobserver agreement: Calculation formulas and distribution effects. Journal of Behavioral Assessment, 3(1), 37-57.

Ireri, N. W., White, S. W., \& Mbwayo, A. W. (2019). Treating anxiety and social deficits in children with autism spectrum disorder in two schools in Nairobi, Kenya. Journal of Autism and Developmental Disorders, 49(8), 3309-3315.

Kalvin, C. B., Jordan, R. P., Rowley, S. N., Weis, A., Wood, K. S., Wood, J. J., \& Sukhodolsky, D. G. (2021). Conducting CBT for anxiety in children with autism spectrum disorder during COVID19 pandemic. Journal of Autism and Developmental Disorders, pp. $1-9$.

Kerns, C. M., Kendall, P. C., Berry, L., Souders, M. C., Franklin, M. E., Schultz, R. T., \& Herrington, J. (2014). Traditional and atypical presentations of anxiety in youth with autism spectrum disorder. Journal of Autism and Developmental Disorders, 44(11), 2851-2861.

Kleberg, J. L., Högström, J., Nord, M., Bölte, S., Serlachius, E., \& Falck-Ytter, T. (2017). Autistic traits and symptoms of social anxiety are differentially related to attention to others' eyes in social anxiety disorder. Journal of Autism and Developmental Disorders, 47(12), 3814-3821.
Koh, J. B. K., Chang, W. C., Fung, D. S. S., Kee, C. H. Y., \& Woo, B. S. C. (2002). Validation of a culturally appropriate anxiety scale for Singaporean children. In 49th Annual Meeting of the American Academy of Child and Adolescent Psychiatry (pp. 22-27).

Lickel, A., MacLean, W. E., Blakeley-Smith, A., \& Hepburn, S. (2012). Assessment of the prerequisite skills for cognitive behavioral therapy in children with and without autism spectrum disorders. Journal of Autism and Developmental Disorders, 42(6), 992-1000.

Lipsey, M. W., \& Wilson, D. B. (2001). Practical meta-analysis. SAGE publications, Inc.

Luxford, S., Hadwin, J. A., \& Kovshoff, H. (2017). Evaluating the effectiveness of a school-based cognitive behavioural therapy intervention for anxiety in adolescents diagnosed with autism spectrum disorder. Journal of Autism and Developmental Disorders, 47(12), 3896-3908.

Lyneham, H. J., Street, A. K., Abbott, M. J., \& Rapee, R. M. (2008). Psychometric properties of the school anxiety scale-Teacher reported (SAS-TR). Journal of Anxiety Disorders, 22(2), 292-300. https://doi.org/10.1016/j.janxdis.2007.02.001

Maenner, M. J., Shaw, K. A., \& Baio, J. (2020). Prevalence of autism spectrum disorder among children aged 8 years-autism and developmental disabilities monitoring network, 11 sites, United States, 2016. MMWR Surveillance Summaries, 69(4), 1.

March, J. S., Sullivan, K., \& Parker, J. (1999). Test-retest reliability of the multidimensional anxiety scale for children. Journal of Anxiety Disorders, 13(4), 349-358.

Moher, D., Liberati, A., Tetzlaff, J., Altman, D. G., \& Prisma Group. (2009). Reprint-preferred reporting items for systematic reviews and meta-analyses: the PRISMA statement. Physical Therapy, 89(9), 873-880

Montes, G., Halterman, J. S., \& Magyar, C. I. (2009). Access to and satisfaction with school and community health services for US children with ASD. Pediatrics, 124(Supplement 4), S407-S413.

Ooi, Y. P., Lam, C. M., Sung, M., Tan, W. T. S., Goh, T. J., Fung, D. S. S., \& Chua, A. (2008). Effects of cognitive-behavioural therapy on anxiety for children with high-functioning autistic spectrum disorders. Singapore Medical Journal, 49(3), 215.

Owens, J. S., Lyon, A. R., Brandt, N. E., Warner, C. M., Nadeem, E., Spiel, C., \& Wagner, M. (2014). Implementation science in school mental health: Key constructs in a developing research agenda. School Mental Health, 6(2), 99-111.

Perihan, C., Burke, M., Bowman-Perrott, L., Bicer, A., Gallup, J., Thompson, J., \& Sallese, M. (2020a). Effects of cognitive behavioral therapy for reducing anxiety in children with high functioning ASD: A systematic review and meta-analysis. Journal of Autism and Developmental Disorders, 50(6), 1958-1972.

Perihan C., Burke M.D., Bowman-Perrott L., Gallup J. (2020) Cognitive Behavioral Therapy (CBT) and ASD. In: Volkmar F. (eds) Encyclopedia of Autism Spectrum Disorders. Springer, New York, NY. https://doi.org/10.1007/978-1-4614-6435-8_102461-1

Peters-Scheffer, N., Didden, R., Korzilius, H., \& Sturmey, P. (2011). A meta-analytic study on the effectiveness of comprehensive ABA-based early intervention programs for children with autism spectrum disorders. Research in Autism Spectrum Disorders, 5(1), 60-69.

Reaven, J., Blakeley-Smith, A., Nichols, S., \& Hepburn, S. (2011). Facing your fears: Group therapy for managing anxiety in children with high-functioning autism spectrum disorders. Baltimore, $M D$ : Brookes.

Reichow, B., \& Volkmar, F. R. (2010). Social skills interventions for individuals with autism: Evaluation for evidence-based practices within a best evidence synthesis framework. Journal of Autism and Developmental Disorders, 40(2), 149-166.

Reynolds, C. R., \& Richmond, B. O. (1985). Revised children's manifest anxiety scale (RCMAS). Manual. 
Rodgers, J., Wigham, S., McConachie, H., Freeston, M., Honey, E., \& Parr, J. R. (2016). Development of the anxiety scale for children with autism spectrum disorder (ASC-ASD). Autism Research, 9(11), 1205-1215.

Rosa, M., Puig, O., Lázaro, L., \& Calvo, R. (2016). Socioeconomic status and intelligence quotient as predictors of psychiatric disorders in children and adolescents with high-functioning autism spectrum disorder and in their siblings. Autism, 20(8), 963-972. https://doi.org/10.1177/1362361315617881

Rutherford, M., \& Johnston, L. (2019). An Autism Evidence Based Practice Toolkit for use with the SCERTS ${ }^{\mathrm{TM}}$ Assessment and Planning Framework.

School-Based Mental Health Services. (2016). Retrieved September 15, 2020, from https://www.nasponline.org/resources-and-publi cations/resources-and-podcasts/mental-health/school-psychologyand-mental-health/school-based-mental-health-services.

Sedgewick, F., Leppanen, J., \& Tchanturia, K. (2020). Gender differences in mental health prevalence in autism. Advances in Autism.

Simonoff, E., Pickles, A., Charman, T., Chandler, S., Loucas, T., \& Baird, G. (2008). Psychiatric disorders in children with autism spectrum disorders: prevalence, comorbidity, and associated factors in a population-derived sample. Journal of the American Academy of Child \& Adolescent Psychiatry, 47(8), 921-929.

Sofronoff, K., Attwood, T., \& Hinton, S. (2005). A randomised controlled trial of a CBT intervention for anxiety in children with Asperger syndrome. Journal of Child Psychology and Psychiatry, 46(11), 1152-1160.

SPARK. (2020). Impact of COVID-19 on families and children with autism. Simons Foundation.

Silverman, W. K., \& Albano, A. M. (1996). The anxiety disorders interview schedule for DSM IV-Child and parent versions. San Antonio, TX: Graywind.

Spence, S. H. (1998). A measure of anxiety symptoms among children. Behaviour Research and Therapy, 36(5), 545-566.

Spence, S. H. (1997). Structure of anxiety symptoms among children: A confirmatory factor-analytic study. Journal of Abnormal Psychology, 106(2), 280-297.

Sterne, J. A., \& Egger, M. (2001). Funnel plots for detecting bias in meta-analysis: Guidelines on choice of axis. Journal of Clinical Epidemiology, 54(10), 1046-1055.
Sukhodolsky, D. G., Scahill, L., Gadow, K. D., Arnold, L. E., Aman, M. G., McDougle, C. J., \& Vitiello, B. (2008). Parent-rated anxiety symptoms in children with pervasive developmental disorders: Frequency and association with core autism symptoms and cognitive functioning. Journal of Abnormal Child Psychology, $36(1), 117-128$.

Trudgen, M., \& Lawn, S. (2011). What is the threshold of teachers' recognition and report of concerns about anxiety and depression in students? An exploratory study with teachers of adolescents in regional Australia. Journal of Psychologists and Counsellors in Schools, 21(2), 126-141.

Van Steensel, F. J., Bögels, S. M., \& Perrin, S. (2011). Anxiety disorders in children and adolescents with autistic spectrum disorders: A meta-analysis. Clinical Child and Family Psychology Review, 14(3), 302.

Vasa, R. A., \& Mazurek, M. O. (2015). An update on anxiety in youth with autism spectrum disorders. Current Opinion in Psychiatry, $28(2), 83$.

White, S. W., Albano, A., Johnson, C., Kasari, C., Ollendick, T., \& Klin, A. (2010). Development of a cognitive-behavioural intervention program to treat anxiety and social deficits in teens with high-functioning autism. Clinical Child and Family Psychology Review, 13, 77-90.

White, S. W., Ollendick, T., Albano, A. M., Oswald, D., Johnson, C., Southam-Gerow, M. A., \& Scahill, L. (2013). Randomized controlled trial: Multimodal anxiety and social skill intervention for adolescents with autism spectrum disorder. Journal of Autism and Developmental Disorders, 43(2), 382-394.

White, S. W., \& Roberson-Nay, R. (2009). Anxiety, social deficits, and loneliness in youth with autism spectrum disorders. Journal of Autism and Developmental Disorders, 39(7), 1006-1013.

Wood, J. J., \& Gadow, K. D. (2010). Exploring the nature and function of anxiety in youth with autism spectrum disorders. Clinical Psychology: Science and Practice, 17(4), 281-292.

Publisher's Note Springer Nature remains neutral with regard to jurisdictional claims in published maps and institutional affiliations. 